\title{
Impact of Neoadjuvant Chemotherapy on Breast Cancer Biomarkers: A Guide for Further Adjuvant Treatment
}

\author{
Ghada Ezzat Eladawei ${ }^{1, *}$, Dina Abdallah Elnady ${ }^{2}$, Ashraf Khater ${ }^{3}$, Sheref Mohamed El-taher ${ }^{4}$ \\ ${ }^{1}$ Clinical Oncology \& Nuclear Medicine Department, Mansoura University, Mansoura, Eygpt \\ ${ }^{2}$ Pathology Department, Mansoura University, Mansoura, Eygpt \\ ${ }^{3}$ Surgical Oncology Department, Oncology Centre, Mansoura University, Mansoura, Eygpt \\ ${ }^{4}$ Public Health \& Community Medicine Department, Benha University, Benha, Eygpt

\section{Email address:} \\ ghadaeladawy@hot mail.com (G. E. Eladawei), dr.dina.elnady@gmail.com (D. A. Elnady), dr.ashrafkhater@yahoo.com (A. Khater), \\ sherefmoh@gmail.com (S. M. El-taher) \\ ${ }^{*}$ Corresponding author
}

\section{To cite this article:}

Ghada Ezzat Eladawei, Dina Abdallah Elnady, Ashraf Khater, Sheref Mohamed El-taher. Impact of Neoadjuvant Chemotherapy on Breast Cancer Biomarkers: A Guide for Further Adjuvant Treatment. Cancer Research Journal. Vol. 7, No. 1, 2019, pp. 8-17. doi: $10.11648 /$ j.crj.20190701.12

Received: January 22, 2019; Accepted: February 27, 2019; Published: March 20, 2019

\begin{abstract}
Introduction and objective: There is discrepancy in practice worldwide whether testing molecular profile on residual carcinoma is warranted and if treatment options should be modified according to final molecular profile of tumor. Therefore, the current study was conducted to evaluate potential changes in breast biomarkers; estrogen receptor, progesterone receptor, HER-2 and Ki67 expression before and after neoadjuvant chemotherapy in Egyptian patients with breast cancer. Patients and method: a hundred locally advanced (initial clinical stage IIB-IIIC) breast carcinoma patients were treated by one of two protocols of neoadjuvant chemotherapy. First protocol: 4 cycles of AC (adriamycin, cyclophosamide) repeated every 21 days, followed by 12 weeks of paclitaxel. Second protocol: FAC (fluorouracil, adriamycin, cyclophosamide) or FEC (fluorouracil, epirubicin, cyclophosamide) for 6 cycles to be repeated every 21 days. Immunohistochemisty of breast biomarkers were performed on both initial biopsies and also surgical resection specimens for each patient. Result: There was statistically significant change of $E R(p=0.03$ ). Fifty five tumors were initially negative and thirty nine became negative after neoadjuvant chemotherapy. The rate of conversion from negative to positive was $14 \%$. Forty seven of tumors were initially negative progesterone receptors (PR) and sixty two became negative after neoadjuvant chemotherapy. PR status showed statistically significant change between before and after neoadjuvant chemotherapy $(\mathrm{p}=0.04)$. The rate of conversion of PR from positive to negative was $15 \%$. There is no statistically significant change of HER-2 before and after neoadjuvant chemotherapy $(\mathrm{p}=0.98)$. There is statistically significant change from high to low Ki 67 index $(\mathrm{p}=0.006)$. Rate of conversion changes of Ki 67 from high to low was $20 \%$. Conclusion: neoadjuvant chemotherapy change receptor status and reduce $\mathrm{K}$ i67 expression. This change in hormone receptor status from negative to positive offers new endocrine therapy to this group of patients. Accordingly, reevaluation of hormone receptors after neoadjuvant chemotherapy is required to guide further adjuvant treatment.
\end{abstract}

Keywords: Breast Cancer, Neoadjuvant Chemotherapy, ER, PR, HER2, Ki67

\section{Introduction}

Breast cancer is the most common cancer among women worldwide, including Egypt [1]. Management of patients with primary breast carcinoma is based on several clinical and histological prognostic factors, including age, tumor size, lymph node involvement, histological type, tumor grade as well as estrogen receptor ER, progesterone receptor PR and HER2/neu expression [2].

Neoadjuvant chemotherapy is the standard of care for patients with locally advanced or inflammatory breast cancer and is increasingly being used with the aim of down staging 
and facilitating conservative surgery [3-5]. Testing the tumor core biopsy samples for estrogen receptor (ER) and human epidermal growth factor receptor 2 (HER2) expressions is a prerequisite for selecting patients for neoadjuvant treatment [6]. Furthermore, neoadjuvant chemotherapy assesses tumor sensitivity to systemic therapy. Pathological response to neoadjuvant chemotherapy has prognostic significance independent of other prognostic biological markers [7].

To this day, the first biomarkers recommended for routine clinical use are hormone receptors and human epidermal growth factor receptor 2 (HER-2). They have most extreme significance in treatment planning [8, 9]. Traditionally, targeted therapies against estrogen receptor, progesterone receptor and HER-2 are based on initial tumor characteristics. Moreover, ER, PR and HER-2 beside the proliferative marker Ki67 can serve as surrogates to help approximate the intrinsic biologic subtypes utilized in modern-day oncology, such luminal A [10]. Also, they have predictive value, giving valuable data for assessing response to different types of treatment. Strong estrogen receptor expression often predicts good response to anti-estrogen therapy and good clinical outcome, and on the other hand correlates negatively with chemotherapy response $[11,12]$.

The impact of neoadjuvant chemotherapy on breast cancer biomarker remains controversial. In this regard, there is disagreement of results of previous studies ranging from no alteration [13] to $61 \%$ changes of estrogen receptor status following neoadjuvant chemotherapy [14]. Also, reported data on HER2 status varies from no change [15] to $43 \%$ switch of HER2 status [16].

There is an ongoing debate about the rate of change of hormone receptors, HER2 expression after neoadjuvant chemotherapy, furthermore there is discrepancy in practice worldwide whether testing molecular profile on residual carcinoma is warranted and if treatment options should be modified according to final molecular profile of tumor. So, the current study was conducted to evaluate potential changes in hormonal receptors ER, PR, HER2 and Ki67 expressions before and after neoadjuvant chemotherapy in Egyptian patients with breast cancer.

\section{Patients and Methods}

After approving by Institutional Review Board of Mansoura faculty of Medicine

(IRB-MFM), this prospective study was conducted at the Clinical Oncology \& nuclear Medicine department, in collaboration with the surgical oncology \& pathology departments, Mansoura University, in the period between January 2014 to December 2017.

\subsection{Inclusion Criteria}

Patients included in this study had the following criteria: unilateral primary breast cancer (proved pathologically invasive breast cancer), Clinical stage IIB-IIIC, Good performance status $(\mathrm{ECOG} \leq 2)$ and had adequate liver, kidney and hematological functions.

\subsection{Exclusion Criteria}

Patients were excluded from this study, if the patient presented with inflammatory breast cancer or Stage IV breast cancer and patients who had excision of primary tumor prior to neoadjuvant chemotherapy. Absence of residual tumor for analysis of hormone receptor immunohistochemistry as result of neoadjuvant chemotherapy complete response was also excluded.

\subsection{Base Line Workup}

Include clinical examination, bilateral sonomammogram, core biopsy or incisional biopsy for histopathological diagnosis. Metastatic work up was done to roll out distant metastasis by computed tomography of the chest and abdomen and bone scan.

Staging was performed according to the sixth edition of the American Joint Committee on Cancer (AJCC) staging manual for breast cancer. When invasive adenocarcinoma was documented, grade, Hormonal receptors (estrogen and progesterone), HER2 and Ki67 were demonstrated.

\subsection{Treatment Plan}

Patients were treated by one of two protocols of neoadjuvant chemotherapy.

First protocol: 4 cycles of AC (adriamycin, cyclophosamide) repeated every 21 days, followed by 12 weeks of paclitaxel.

Second protocol: FAC (fluorouracil, adriamycin, cyclophosamide) or FEC (fluorouracil, epirubicin, cyclophosamide) for 6 cycles to be repeated every 21 days.

Complete blood cell counts, serum creatinine and complete liver functions were required before each cycle. Anti-emetic and supportive cares were given for each patient as required.

Surgery was done after one month from the end of last cycle chemotherapy. All patients received postoperative radiation therapy (adjuvant). Patients with positive estrogen or progesterone receptor were treated with hormonal therapy regardless of any change of the status of hormonal receptors.

\subsection{Evaluation of Response to Neoadjuvant Chemotherapy}

Patients who had no remaining invasive cancer in the breast (pT0) and who were lymph node negative (pN0) were considered to have a pathological complete response ( $p \mathrm{CR}$ ). The tumor response to neoadjuvant chemotherapy was evaluated pathologically by classifying the regressive changes using a semi- quantitative scoring system from 0 to 4 $(0=$ no effect, $1=$ resorption and tumor sclerosis, $2=$ minimal residual invasive tumor $[<0.5 \mathrm{~cm}], 3=$ residual non-invasive tumor only, $4=$ no tumor detectable) according to the tumor regression grading described by Sinn et al. [17].

\subsection{Immunohistochemical Markers}

Immunohistochemistry techinques: the primary antibodies used were ER (DAKO USA, clone 1D5; 1:25), PR (DAKO USA, clone PgR636; 1:50), HER2 (DAKO USA, clone. c- 
erbB-2 Oncoprotein) \&Ki67 (DAKO USA, clone MIB-1). Detection kit used high sensitive kit (Dako Cytomation envision +dual link system peroxidase code K4061) using $\mathrm{DAB}$ as chromagen. Proper positive control for ER, PR \& Her2 is normal breast tissue, Burkitt lymphoma for Ki67. Negative control was prepared without addition of primary antibody.

Immunohistochemical analyses (IHC) for ER, PR, HER/ neu and Ki-67 were performed on both initial biopsies and also surgical resection specimens for each patient. ER and PR are nuclear receptors. In Allred system of scoring, Proportion score [PS] is given to the cells depending on the proportion of cells which are stained. PS is ranging from 0 to $5(0=$ No cells are positive, $1=<1 \%$ cells are positive , $2=1-10 \%$ cells are positive $3=11-33 \%$ cells are positive , $4=34-66 \%$ cells are positive , $5=67-100 \%$ cells are positive). Intensity score [IS] is given depending on the intensity of staining. Intensity score is ranging from $0-3 \quad(0=$ Negative, $1=$ weak, $2=$ Intermediate, $3=$ Strong). By adding the PS and IS, we can calculate the final Allred score (PS + IS $=$ AS) [18].

HER2/neu is a cell membrane receptor and depending on the intensity of staining a score of $0-3$ is given to the cells ( 0 : no staining or membrane staining in $<10 \%$ of tumor cells, $+1:>10 \%$ of tumor cells with faint positive incomplete membrane staining, $+2:>10 \%$ of tumor cells with weak to moderate staining of the entire membrane, $+3:>30 \%$ of tumor cells with strong staining of the entire membrane). Ki67 is a nuclear protein. The Ki67 immunohistochemically stained slides for Ki67 marker were divided into 2 groups; low and high risk as the $20 \%$ Ki67 cut-off [19].

\subsection{Statistical Analysis}

Descriptive statistics will be provided to summarize the patient characteristics. Analysis of pre- and post-treatment categorical variables including tumor type, grade, ER, PR and HER2 scores was done using the chi-square test.

Receptor status was also divided into negative and positive using a cut-off value of Allred score 2 for ER/PR. Fisher's exact test was used to compare receptor conversion rate between pretreatment and post treatment variables. All comparisons were two-sided and $p$ value of $\leq 0.05$ was considered significant. All statistical tests were performed with SPSS statistics version 21.

\section{Results}

This is prospective, observational study. Clinicopathological characteristics of 100 eligible breast cancer patients are shown in table 1. Median age was 45 years (range 26 - 67 years). $89 \%$ of patients were premenopausal. $29 \%$ of patients had stage IIB, $71 \%$ had stage III. $87 \%$ of patients diagnosed with true cut biopsy. The majority of tumors $(93 \%)$ were invasive ductal carcinoma. There were only 2 (2\%) grade I tumor, 49 (49\%) grade II, and $49(49 \%)$ grade III tumors. $45 \%$ of patients had positive estrogen receptor and $53 \%$ of patients had positive progesterone receptor. HER-2 receptor was over expressed in
28 patients. 52 patient received anthracycline combination and 48 patients received taxane/anthracycline combination. $51 \%$ of patients underwent breast conservation surgery after neoadjuvant chemotherapy.

Table 2 outlines patients and tumor characteristics regarding treatment protocols. The two groups were balanced in all clinicopathological characteristics except, younger patients received anthracycline combination than those received taxane / anthracycline combination and $71.2 \%$ of patients who received anthracycline combination achieved pathological response score 2 and 3.

\subsection{Changes in Hormonal Receptors Expression}

Pre and post neoadjvant chemotherapy of ER, PR was available for 100 patients (table 3). Cut- off 2/8 Allred score was used to define positivity for ER and PR. There was statistically significant change of ER $(p=0.03)$. Fifty five tumors were initially negative and thirty nine became negative after neoadjuvant chemotherapy. The rate of conversion from negative to positive was 14\% (Figure 1). Forty seven of tumors were initially negative progesterone receptors (PR) and sixty two became negative after neoadjuvant chemotherapy. PR status showed statistically significant change between before and after neoadjuvant chemotherapy $(p=0.04)$. The rate of conversion of PR from positive to negative was $15 \%$.

\subsection{Changes in HER-2 neu Expression}

HER-2 neu status was evaluated by IHC. Pre and post neoadjuvant chemotherapy of HER-2 neu presented in table 3 . Twenty eight (28\%) patients had over expression of HER2 before neoadjuvant chemotherapy. After neoadjuvant chemotherapy twenty three $(23 \%)$ patients had over expressed HER-2. There is no statistically significant change of HER-2 before and after neoadjuvant chemotherapy $(\mathrm{p}=0.98)$ table 3 , (Figure 2).

\subsection{Changes in Ki67 Expression}

Fifty one (51\%) of tumors demonstrated high Ki67 proliferation index before neoadjuvant chemotherapy. There is statistically significant change from high to low $\mathrm{Ki} 67$ index ( $\mathrm{p}=0.006$ ) table 3 . Rate of conversion changes of $\mathrm{Ki} 67$ from high to low was $20 \%$ (Figure 3 ).

\subsection{Changes in Breast Biomarkers in Relation to Chemotherapy Regimen}

In patients who received anthracycline combination (FEC or FAC protocols), there is no significant change of estrogen receptor or progesterone receptor or HER-2 status. There is significant change of Ki67 from high to low expression ( $p=$ 0.04 ) table 4. Significant change of estrogen receptors was observed in patients received anthracycline /taxanes combination from negative to positive $(p=0.01)$. There is significant change of $\mathrm{Ki} 67$ from high to low expression $(p=0.03)$. There is no significant change of progesterone receptor status or HER-2 expression table 5. 
Table 1. Patients and tumor characteristics.

\begin{tabular}{|c|c|c|}
\hline characteristic & Number $=100$ & Percentage \% \\
\hline Age median & 45 years & \\
\hline range & $26-67$ years & \\
\hline mean & $46.5 \pm 10.4$ & \\
\hline \multicolumn{3}{|l|}{ Menopausal status } \\
\hline Premenopausal & 89 & $89 \%$ \\
\hline Postmenopausal & 11 & $11 \%$ \\
\hline \multicolumn{3}{|l|}{ Clinical TNM stage (before NAC) } \\
\hline IIB & 29 & $29 \%$ \\
\hline IIIA & 45 & $45 \%$ \\
\hline IIIB & 25 & $25 \%$ \\
\hline IIIC & 1 & $1 \%$ \\
\hline \multicolumn{3}{|l|}{ Type of biopsy } \\
\hline Excisional biopsy & 13 & $13 \%$ \\
\hline True cut biopsy & 87 & $87 \%$ \\
\hline \multicolumn{3}{|l|}{ Pathology } \\
\hline Invasive ductal carcinoma & 93 & $93 \%$ \\
\hline Invasive lobular carcinoma & 7 & $7 \%$ \\
\hline \multicolumn{3}{|l|}{ Tumor grade } \\
\hline Grade I & 2 & $2 \%$ \\
\hline Grade II & 49 & $49 \%$ \\
\hline Grade III & 49 & $49 \%$ \\
\hline \multicolumn{3}{|l|}{ Estrogen receptor (before NAC) } \\
\hline Positive & 45 & $45 \%$ \\
\hline Negative & 55 & $55 \%$ \\
\hline \multicolumn{3}{|l|}{ Progesterone receptor (before NAC) } \\
\hline Positive & 53 & $53 \%$ \\
\hline Negative & 47 & $47 \%$ \\
\hline \multicolumn{3}{|l|}{ HER-2 receptor ( before NAC) } \\
\hline Positive & 28 & $28 \%$ \\
\hline Negative & 72 & $72 \%$ \\
\hline \multicolumn{3}{|l|}{ Ki 67 (before NAC) } \\
\hline High & 51 & $51 \%$ \\
\hline Low & 49 & $49 \%$ \\
\hline \multicolumn{3}{|l|}{ Neoadjuvant chemotherapy } \\
\hline Anthracycline combination & 52 & $52 \%$ \\
\hline Taxane/ anthracycline combination & 48 & $48 \%$ \\
\hline \multicolumn{3}{|l|}{ Surgery } \\
\hline Breast conservative surgery & 51 & $51 \%$ \\
\hline Mastectomy & 49 & $49 \%$ \\
\hline \multicolumn{3}{|l|}{ Pathological response } \\
\hline No effect (score 0 ) & 6 & $6 \%$ \\
\hline Resorption and tumor sclerosis ( score 1) & 34 & $34 \%$ \\
\hline Minimal residual invasive (score 2) & 41 & $41 \%$ \\
\hline Residual non invasive tumor (score 3) & 19 & $19 \%$ \\
\hline
\end{tabular}

Table 2. Patients and tumor characteristics regarding treatment protocol.

\begin{tabular}{|c|c|c|c|c|c|c|}
\hline \multicolumn{2}{|l|}{ Characteristic } & \multicolumn{2}{|c|}{ Anthracycline combination } & \multicolumn{2}{|c|}{ Taxane/anthracycline combination } & \multirow{2}{*}{$\frac{\text { p-value }}{<0.001}$} \\
\hline Age & & $41.2 \pm 8.7$ & & $52.3 \pm 8.9$ & & \\
\hline \multirow{2}{*}{ Menopausal status } & Premenopausal & 49 & $94.2 \%$ & 40 & $83.3 \%$ & \multirow{2}{*}{0.08} \\
\hline & Postmenopausal & 3 & $5.8 \%$ & 8 & $16.7 \%$ & \\
\hline \multirow{2}{*}{ Type of biopsy } & Excisional biopsy & 6 & $11.5 \%$ & 7 & $14.6 \%$ & \multirow{2}{*}{0.65} \\
\hline & True cut biopsy & 46 & $88.5 \%$ & 41 & $85.4 \%$ & \\
\hline \multirow{4}{*}{ Clinical Stage } & IIB & 17 & $32.7 \%$ & 12 & $25 \%$ & \multirow{4}{*}{0.12} \\
\hline & IIIA & 26 & $50.0 \%$ & 19 & $39.6 \%$ & \\
\hline & IIIB & 8 & $15.4 \%$ & 17 & $35.4 \%$ & \\
\hline & IIIC & 1 & $1.9 \%$ & 0 & $0.0 \%$ & \\
\hline
\end{tabular}




\begin{tabular}{|c|c|c|c|c|c|c|}
\hline \multicolumn{2}{|l|}{ Characteristic } & \multicolumn{2}{|c|}{ Anthracycline combination } & \multicolumn{2}{|c|}{ Taxane/anthracycline combination } & \multirow{3}{*}{$\begin{array}{l}\text { p-value } \\
0.4\end{array}$} \\
\hline \multirow{2}{*}{ Pathology } & IDC & 50 & $96.2 \%$ & 43 & $89.6 \%$ & \\
\hline & ILC & 2 & $3.8 \%$ & 5 & $10.4 \%$ & \\
\hline \multirow{3}{*}{ Tumor grade } & Grade I & 0 & $0.0 \%$ & 2 & $4.2 \%$ & \multirow{3}{*}{0.09} \\
\hline & Grade II & 22 & $42.3 \%$ & 27 & $56.3 \%$ & \\
\hline & Grade III & 30 & $57.7 \%$ & 19 & $39.5 \%$ & \\
\hline \multirow{2}{*}{$\begin{array}{l}\text { Estrogen receptor (before } \\
\text { NAC) }\end{array}$} & Negative & 30 & $57.7 \%$ & 25 & $52.1 \%$ & \multirow{2}{*}{0.6} \\
\hline & positive & 22 & $42.3 \%$ & 23 & $47.9 \%$ & \\
\hline \multirow{2}{*}{$\begin{array}{l}\text { Progesterone receptor } \\
\text { (before NAC) }\end{array}$} & negative & 20 & $38.5 \%$ & 27 & $56.2 \%$ & \multirow{2}{*}{0.08} \\
\hline & positive & 32 & $61.5 \%$ & 21 & $43.8 \%$ & \\
\hline \multirow{2}{*}{$\begin{array}{l}\text { HER-2 receptor (before } \\
\text { NAC) }\end{array}$} & Negative & 36 & $69.2 \%$ & 36 & $75.0 \%$ & \multirow{2}{*}{0.81} \\
\hline & Positive & 16 & $30.8 \%$ & 12 & $25.0 \%$ & \\
\hline \multirow{2}{*}{ KI67 (before NAC) } & high & 31 & $59.6 \%$ & 20 & $41.7 \%$ & \multirow{2}{*}{0.07} \\
\hline & low & 21 & $40.4 \%$ & 28 & $58.3 \%$ & \\
\hline \multirow{2}{*}{ Surgery } & CBS & 28 & $53.8 \%$ & 23 & $47.9 \%$ & \multirow{2}{*}{0.6} \\
\hline & MRM & 24 & $46.2 \%$ & 25 & $52.1 \%$ & \\
\hline \multirow{2}{*}{ Postoperative pathology } & IDC & 51 & $98.1 \%$ & 44 & $91.7 \%$ & \multirow{2}{*}{0.14} \\
\hline & ILC & 1 & $1.9 \%$ & 4 & $8.3 \%$ & \\
\hline \multirow{4}{*}{ Pathologic response } & no effect (score 0 ) & 4 & $7.7 \%$ & 2 & $4.2 \%$ & \multirow{4}{*}{0.04} \\
\hline & resorption and tumor sclerosis (score 1) & 11 & $21.2 \%$ & 23 & $47.9 \%$ & \\
\hline & minimal residual invasive ( score 2 ) & 24 & $46.2 \%$ & 17 & $35.4 \%$ & \\
\hline & residual non invasive tumor ( score 3 ) & 13 & $25.0 \%$ & 6 & $12.5 \%$ & \\
\hline
\end{tabular}

Table 3. Changes in breast biomarkers before and after neoadjuvant chemotherapy.

\begin{tabular}{|c|c|c|c|c|c|c|}
\hline Characteristic & & Bef & & After & & p-value \\
\hline \multirow{2}{*}{ Estrogen receptor } & negative & 55 & $55 \%$ & 39 & $39 \%$ & \multirow{2}{*}{0.03} \\
\hline & positive & 45 & $45 \%$ & 38 & $61 \%$ & \\
\hline \multirow{2}{*}{ Progesterone receptor } & negative & 47 & $47 \%$ & 62 & $62 \%$ & \multirow{2}{*}{0.04} \\
\hline & positive & 53 & $53 \%$ & 38 & $38 \%$ & \\
\hline \multirow{2}{*}{ HER-2 receptor } & Negative & 72 & $72 \%$ & 77 & $77 \%$ & \multirow{2}{*}{0.2} \\
\hline & Positive & 28 & $28 \%$ & 23 & $23 \%$ & \\
\hline \multirow{2}{*}{ Ki67 } & high & 51 & $51 \%$ & 31 & $31 \%$ & \multirow{2}{*}{0.006} \\
\hline & low & 49 & $49 \%$ & 69 & $69 \%$ & \\
\hline
\end{tabular}

Table 4. Changes in breast biomarkers in relation to anthracycline combination protocol.

\begin{tabular}{|c|c|c|c|c|c|c|}
\hline Characteristic & & Bef & & After & & p-value \\
\hline \multirow{2}{*}{ Estrogen receptor } & negative & 30 & $57.7 \%$ & 27 & $51.9 \%$ & \multirow{2}{*}{0.6} \\
\hline & positive & 22 & $42.3 \%$ & 25 & $48.1 \%$ & \\
\hline \multirow{2}{*}{ Progesterone receptor } & negative & 20 & $38.5 \%$ & 29 & $55.8 \%$ & \multirow{2}{*}{0.08} \\
\hline & positive & 32 & $61.5 \%$ & 23 & $44.2 \%$ & \\
\hline \multirow{2}{*}{ HER-2 receptor } & Negative & 36 & $69.2 \%$ & 40 & $76.9 \%$ & \multirow{2}{*}{0.4} \\
\hline & Positive & 16 & $30.8 \%$ & 12 & $23.1 \%$ & \\
\hline \multirow{2}{*}{ KI67 } & high & 31 & $59.6 \%$ & 22 & $42.3 \%$ & \multirow{2}{*}{0.04} \\
\hline & low & 21 & $40.4 \%$ & 30 & $57.7 \%$ & \\
\hline
\end{tabular}

Table 5. Changes in breast biomarkers in relation to anthracycline/Taxanes combination protocol.

\begin{tabular}{lllllll}
\hline Characteristic & & Before & & After & p-value \\
\hline \multirow{2}{*}{ Estrogen receptor } & negative & 25 & $52.1 \%$ & 12 & $25.0 \%$ & 0.01 \\
& positive & 23 & $47.9 \%$ & 36 & $75.0 \%$ & \\
\multirow{2}{*}{ Progesterone receptor } & negative & 27 & $56.2 \%$ & 33 & $68.8 \%$ & 0.3 \\
& positive & 21 & $43.8 \%$ & 15 & $31.2 \%$ & \\
\multirow{3}{*}{ HER-2 receptor } & negative & 36 & $75.0 \%$ & 37 & $77.1 \%$ & 0.6 \\
\multirow{2}{*}{ KI67 } & positive & 12 & $25.0 \%$ & 11 & $22.9 \%$ & \\
& high & 20 & $41.7 \%$ & 9 & $18.8 \%$ & 0.03 \\
\hline
\end{tabular}




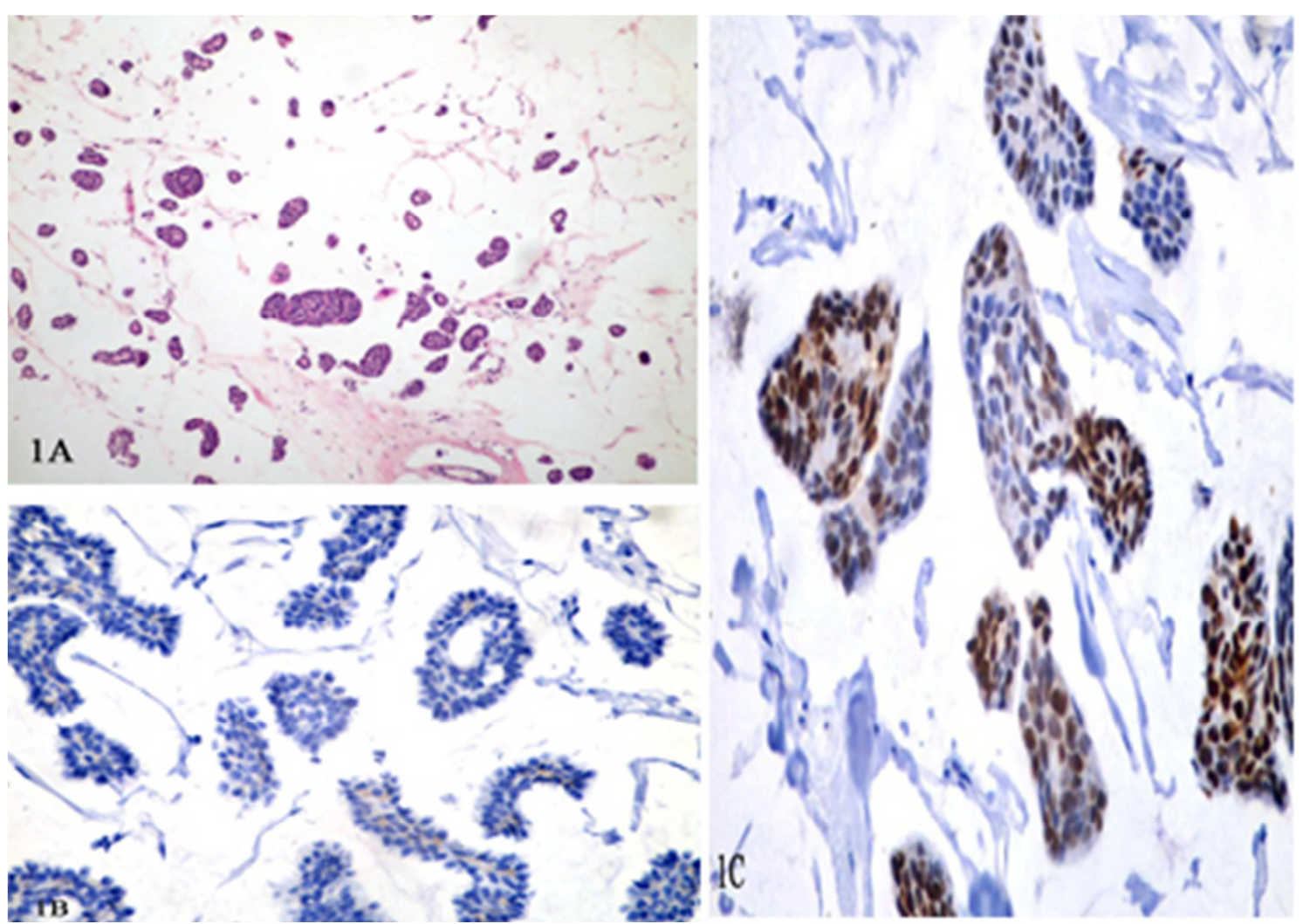

Figure 1. (A) mucinous carcinoma by hematoxylin-eosin revealed sheets of malignant cells floats in pools of mucin original magnification x100). (B) Tumor cells show negative staining of ER before neoadjuvant therapy (original magnification $\times 400$ ). (C) Tumor cells show positive moderate nuclear staining of ER in (11-33\%) of tumor cells (ER 5/8) after neoadjuvant therapy (original magnification x400.

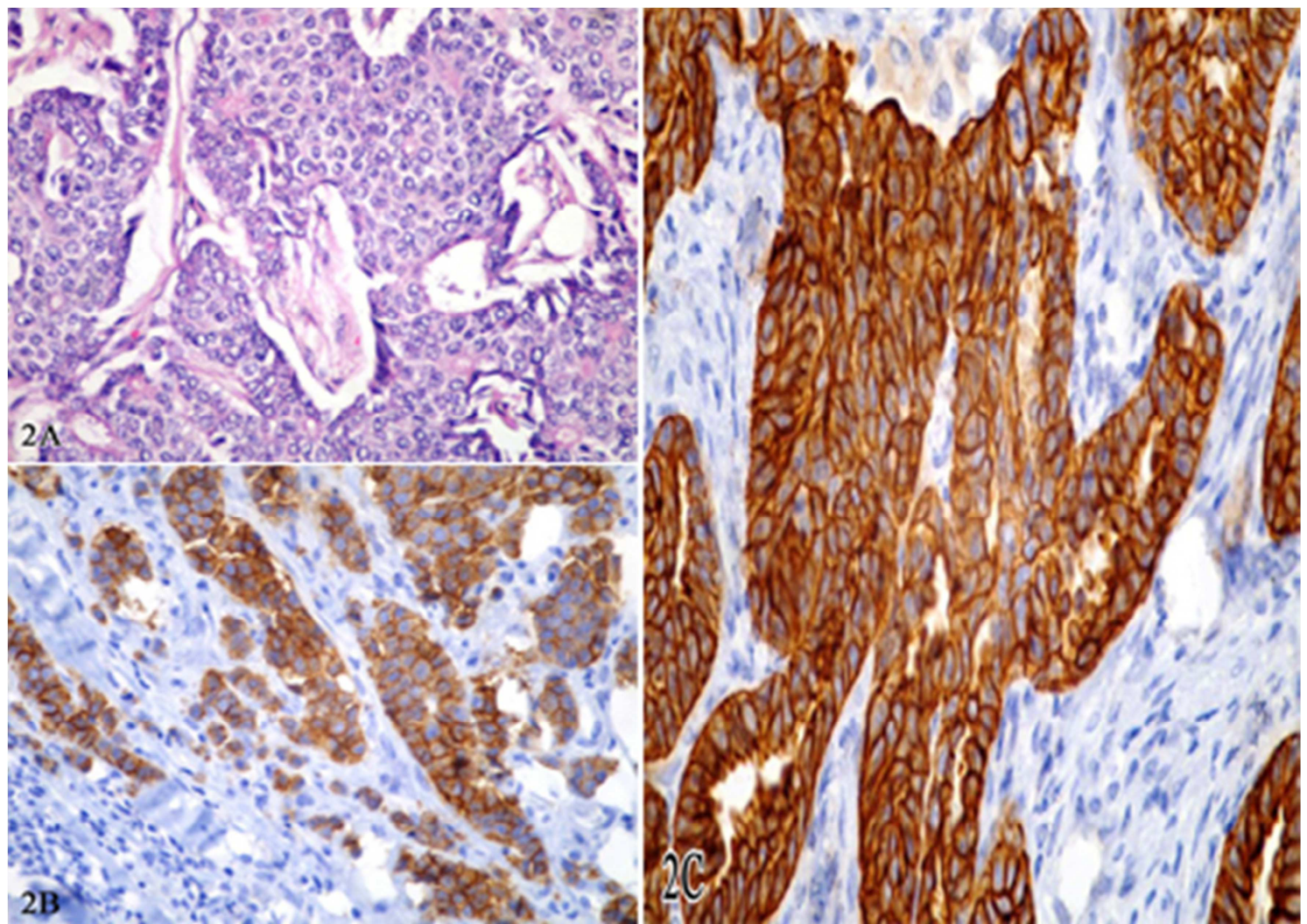

Figure 2. (A) IDC by hematoxylin-eosin revealed sheets of malignant cells with pleomorphic and large nuclei. (B) Tumor cells show positive membranous staining of Her 2 in $>10 \%$ of tumor cells with weak to moderate staining intensity. (Her $2+2)$ before neoadjuvant therapy (C) Tumor cells show positive membranous staining of Her 2 in $>30 \%$ of tumor cells with strong staining intensity (Her2 +3 ) after neoadjuvant therapy (original magnification $x 400)$. 

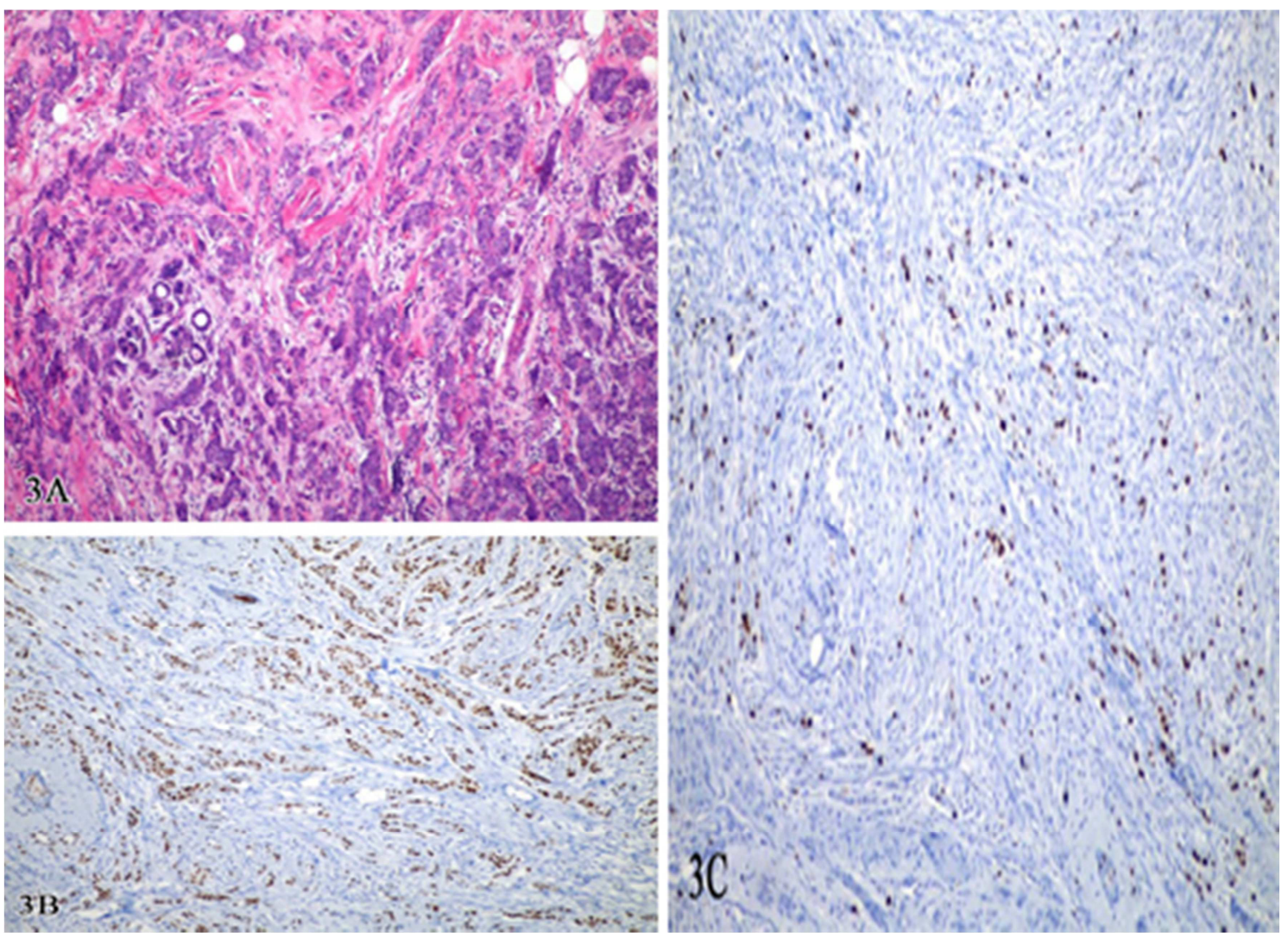

Figure 3. (A) IDC by hematoxylin-eosin revealed sheets \& strands of malignant cells with pleomorphic nuclei surrounded by desmplastic stroma. (B) Tumor cells show nuclear staining of Ki67 in $>20 \%$ of tumor cells (high Ki67) before neoadjuvant therapy (C) Tumor cells show nuclear staining of Ki67 in < 20\% of tumor cells (low Ki67) after neoadjuvant therapy (original magnification x100).

\section{Discussion}

Neoadjuvant chemotherapy is a valuable strategy in the multidisciplinary treatment of breast cancer. Neoadjuvant chemotherapy showed many advantages over adjuvant chemotherapy. Neoadjuvant chemotherapy eliminates possible occult micrometastases in distant organs; facilitate breast conservative surgery, Also assessment of primary tumor response to chemotherapy and furthermore indicates the regimen who achieved significant tumor regression [20].

Neoadjuvant chemotherapeutic agents are known to induce intracellular changes that lead to cell death. The changes in the molecular properties of the cancer cells may affect tumor behavior, tumor biomarkers, tumor grade, properties of the tumor cells and tumor proliferation rates [21].

Impact of neoadjuvant chemotherapy on breast biomarkers is controversially discussed, with some studies reported no significant change and others showed significant changes in the expression [13, 22, 23]. A review of literature published in 2011 revealed 32 relevant studies that discussed impact of neoadjuvant chemotherapy with or without trastuzmab on hormone receptors and HER-2, this review reported that discordance of hormone receptors was reported in four out of eight studies in $8-33 \%$ of patients [24].

The current study observed statistically significant change of hormonal receptors ( $14 \%$ for ER, $15 \%$ PR) of tumors after neoadjuvant chemotherapy. There are no significant changes of HER-2 neu expression. Our observation in hormone receptors change was similar to result of recently published study that reported significant switch of hormone receptor ( $12 \%$ for estrogen receptor from negative to positive, $14.5 \%$ for progesterone from positive to negative [25].

Another study showed that the rates of ER and PR positivity at diagnosis and after neoadjuvant chemotherapy were $44-32.8 \%$, and $43-29.7 \%$, respectively. Negative-topositive change in HR status was observed in five patients [26].

Trifunovic etal [27] reported $9.4 \%$ change in hormone receptor status ( $5 \%$ in ER and $14.5 \%$ in PR). Furthermore, others reported up to $23.8 \%$ conversion in estrogen receptor and or progesterone receptor after neoadjuvant chemotherapy [28].

Some authors noticed significant loss of progesterone receptor positivity only after neoadjuvant chemotherapy and estrogen receptor did not show any significant change [29, 30].

This study showed no significant change of HER-2 expression before and after neoadjuvant chemotherapy which in accordance [29]. However others reported significant change of HER2 (7.1\%) (25), 24-21\% (26), and 4.7\% [27].

The current study reported statistically significant change from high to low Ki 67 index ( $\mathrm{p}=0.006$ ). Rate of conversion changes of Ki 67 from high to low was $20 \%$, similarly to other published studies, Trifunovic etal [27] reported Ki-67 changed in 17 (11.8\%) patients from high to low and Jin G et 
al (21) showed change in Ki-67 expression by $54.3 \%$, to $70.6 \%$, after various neoadjuvant chemotherapy regimens. Also, Avci et al [31] showed only significant changes in $\mathrm{Ki}$ 67 and HER-2 after neoadjuvant chemotherapy.

In the current study, there is no significant change of estrogen receptor or progesterone receptor in patients who received anthracycline combination (FEC or FAC protocols), similarly to Pedrini et al [32] used anthracycline based chemotherapy and showed no change in ER and PR.

There are possible several explanations for the difference in conclusions of previous studies. First, patients received different chemotherapy protocols with various numbers of cycles. Also, over the last few years, assessment of expression of estrogen receptor, progesterone receptor, and HER-2 neu has been evolved dramatically. Earlier studies analyzed the concentration of ER in whole samples in cytosol of whole tissue extracts [33], which included non-tumorous components such as normal breast, stroma, inflammatory cells and also in situ disease. The cut-off values to define hormone positivity was variable at 1\% [34] 5\% [35] and 10\% [36] with some studies using the Allred score (37) as per the current study. Finally, patient number varied from few numbers [33, 38, 39] to larger cohorts [34, 35].

Neoadjuvant chemotherapy exerts modulatory effect on hormone receptor status and other breast biomarkers. Possible explanations of this phenomenon are that

Chemotherapy attacks sensitive cells and leaving insensitive cells. The conversion of receptor status may be a survival mechanism of cancer cells [24]. Also as result of chemotherapy, low circulating level of estrogen may lead to down regulation of hormone receptors and estrogen independent growth [40]. Furthermore, estrogen receptor, progesterone receptor and Her-2 are highly inter-dependent and modulating one receptor can change the others [41].

Clinical practice guidelines of American Society of Clinical Oncology (ASCO) recommended re-biopsy of recurrent and metastatic breast cancer to re-evaluate estrogen receptor, progesterone receptor and Her 2/neu expression [42]. However, there are no ASCO guidelines recommended for re-evaluation of breast biomarkers on residual tumor after neoadjuvant chemotherapy. Hence, practice differs worldwide. Some centers repeat breast biomarkers on residual tumors after neoadjuvant chemotherapy. Others depend on pretreatment assessment.

\section{Conclusion}

This study is exploratory analysis and was conducted on Egyptian patients. Breast cancer patients were treated individually according to each patient characteristic. The current study observed that neoadjuvant chemotherapy changed receptor status and reduced K i67 expression. Change of hormone receptor status from negative to positive offers new endocrine therapy to this group of patients. Accordingly, reevaluation of hormone receptors after neoadjuvant chemotherapy is required to guide further adjuvant treatment.

\section{References}

[1] Azim HA and Ibrahim A S, Breast cancer in Egypt, China and Chinese: statistics and beyond, J Thorac Dis, 2014 Jul; 6(7):864-866.

[2] Harris L, Fritsche H, Mennel R, Norton L, Ravdin P, Taube S, et al. American Society of Clinical Oncology 2007 update of recommendations for the use of tumour markers in breast cancer. J Clin Oncol. 2007; 25: 5287-312.

[3] Thompson AM, Moulder-Thompson SL. Neoadjuvant treatment of breast cancer. Ann Oncol 2012; 23(Suppl. 10): $\mathrm{x} 231 \mathrm{e} 6$.

[4] Kaufmann M, von Minckwitz G, Smith R, Valero V, Gianni L, Eiermann $\mathrm{W}$ et al. International expert panel on the use of primary (preoperative) systemic treatment of operable breast cancer: reveiw and recommendations. J Clin Oncol. 2003; 21: 2600-2608.

[5] Loibl S, von Minckwitz G, Raab G, Blohmer JU, Dan Costa S, Gerber B, et al. Surgical procedures after neoadjuvant chemotherapy in operable breast cancer: results of the GEPARDUO trial. Ann Surg Oncol. 2006; n13: 1434-1442.

[6] National Institute for Health and Care Excellence. Early and locally advanced breast cancer: diagnosis and treatment, NICE guidelines [CG80]. NICE; 2009.

[7] Guarneri V, Broglio K, Kau S. W , Cristofanilli M, Buzdar AU, Valero V et al., Prognostic value of pathologic complete response after primary chemotherapy in relation to hormone receptor status and other factors, J. Clin. Oncol. 24(2006)1037-1044.

[8] Zujewski J., Liu E. T, The 1998 St. Gallen's consensus conference: an assessment, J. Natl. Cancer Inst.90 (1998) $1587-1589$

[9] Goldhirsch A, Glick J. H, Gelber R. D, Senn H. J, Meeting highlights: international consensus panel on the treatment of primary breast cancer, J. Natl. Cancer Inst.90 (1998)16011608.

[10] Goldhirsch A, Wood W. C, Coates A. S, Gelber, R. D., Thürlimann, B., Senn, H. J., et al. Strategies for subtypesdealing with the diversity of breast cancer: high lights of the St. Gallen International Expert consensus on the primary therapy of early breast cancer, Ann. Oncol. 22 (2011)17361747.

[11] Paik S, Tang G, Shak S, Kim C, Baker J, Kim W, et al. Gene expression and benefit of chemotherapy in women with node negative, estrogen receptor-positive breast cancer, J. Clin. Oncol. 24(2006)3726-3734.

[12] Gianni L., Zambetti M, Clark K, Baker J, Cronin M, Wu J et al., Gene expression profiles in paraffin-embedded core biopsy tissue predict response to chemotherapy in women with locally advanced breast cancer, J. Clin. Oncol. 23(2005)7265-7277.

[13] Burcombe RJ, Makris A, Richman PI, Daley FM, Noble S, Pittam M, et al. Evaluation of ER, PgR, HER-2 and Ki-67 as predictors of response to neoadjuvant anthracycline chemotherapy for operable breast cancer. Br J Cancer 2005; 92(1): $147 \mathrm{e} 55$. 
[14] Lee SH, Chung MA, Quddus MR, Steinhoff MM, Cady B. The effect of neoadjuvant chemotherapy on estrogen and progesterone receptor expression and hormone receptor status in breast cancer. Am J Surg 2003; 186:348- 350.

[15] Kasami M, Uematsu T, Honda M, Yabuzaki T, Sanuki J, Uchida $\mathrm{Y}$, et al. Comparison of estrogen receptor, progesterone receptor and Her-2 status in breast cancer pre- and post neoadjuvant chemotherapy. Breast 2008; 17(5):523e7.

[16] Hurley J, Doliny P, Reis I, Silva O, Gomez-Fernandez C, Velez $\mathrm{P}$, et al. Docetaxel, cisplatin, and trastuzumab as primary systemic therapy for human epidermal growth factor receptor 2positive locally advanced breast cancer. J Clin Oncol 2006; 24(12):1831e8.

[17] Sinn H. P, Schmid H, Junkermann H , Huober J, Leppien G, Kaufmann M, etal. Histologic regression of breast cancer after primary (neoadjuvant) chemotherapy , GeburtshilfeFrauenheilkund. 54(1994)552-558.

[18] Allred DC, Bustamante MA, Daniel CO, Gaskill HV, Cruz AB Jr. Immunocytochemical analysis of estrogen receptors in human breast carcinomas. Evaluation of 130 cases and review of the literature regarding concordance with biochemical assay and clinical relevance. Arch Surg 1990; 125:107-13.

[19] Bustreo S, Osella-Abate S, Cassoni P, Donadio M, Airoldi M, Pedani F, et al. Optimal Ki67 cut-off for luminal breast cancer prognostic evaluation: a large case series study with a long-term follow-up, Breast Cancer Res Treat (2016) 157:363-371 .

[20] Beresford MJ, Harris AL, Ah-See M, Daley F, Padhani AR, Makris A. The relationship of the neo-angiogenic marker, endoglin, with response to neoadjuvant chemotherapy in breast cancer. Br J Cancer 2006; 95: 1683-1688.

[21] Jin G, Han Y, Liu C, Chen L, Ding B, Xuan S, et al. Evaluation of biomarker changes after administration of various neoadjuvant chemotherapies in breast cancer. Int J Clin Exp Pathol 2015; 8(1):914-921.

[22] Piper G, Patel N, Patel J, Malay M, Julian T. Neoadjuvant chemotherapy for locally advanced breast cancer results in alterations in pre- operative tumor marker status, Am. Surg.70(2004)1103-1106.

[23] Neubauer H, Gall C, Vogel U, Hornung R, Wallwiener D, Solomayer $\mathrm{E}$ etal. Changes in tumour biological markers during primary systemic chemotherapy (PST), AnticancerRes. 28 (2008) 1797-1804.

[24] VandeVen S, Smit V, Dekker T, Nortier J, Kroep J, Discordances in ER, PR and HER2 receptors after neoadjuvant chemotherapy in breast cancer, Cancer Treat. Rev. 37 (2011) 422-430.

[25] Gahlaut R, Bennett A, Fatayer H, Dall B, Sharma N, Velikova $\mathrm{G}$, et al. Effect of neoadjuvant chemotherapy on breast cancer phenotype, ER/PR and HER2 expression -Implications for the practising oncologist. European Journal of Cancer 60 (2016) $40 \mathrm{e} 48$.

[26] Ozmen V , Atasoy A, Bozdogan A, Dincer M, Eralp Y, Tuzlali S. Prognostic value of receptor status change following neoadjuvant chemotherapy in locally advanced breast cancer. Cancer Treatment Communications 4 (2015)89-95.

[27] Trifunovic J, Memisevic N, Nikolin B, Salma S, Dugandzija T, Vidovic V. Modulatory effect of neoadjuvant chemotherapy on the prognosis of patients with breast cancer. JBUON 2017;
22(3): 638-643.

[28] Yang L, Zhong X, Pu T, Qiu Y, Ye F, Bu H. Clinical significance and prognostic value of receptor conversion in hormone receptor positive breast cancers after neoadjuvant chemotherapy. World J Surg Oncol. 2018; 16: 51.

[29] Shubham S, Maan P, Singh M, and Bhardwaj M. Invasive Ductal Carcinoma Breast: How Neoadjuvant Chemotherapy Affects the Status of Estrogen Receptor, Progesterone Receptor and HER2/Neu-A Tertiary Care Centre Study. J Clin Diagn Res. 2017 Jul; 11(7): EC06-EC08.

[30] Reddy O and Apple S. Breast Cancer Biomarker Changes after Neoadjuvant Chemotherapy: A Single Institution Experience and Literature Review Clinics in Oncology 2017 | Volume 2 | Article 1245.

[31] Avci N, Deligonul A, Tolunay S, Cubukcu E, Fatih Olmez O, Ulas A, et al. Neoadjuvant chemotherapy-induced changes in immunohistochemical expression of estrogen receptor, progesterone receptor, HER2, and $\mathrm{Ki}-67$ in patients with breast cancer. J BUON. 2015 Jan-Feb; 20 (1):45-9.

[32] Pedrini JL, Savaris RF, Schorr MC, Cambruzi E, Grudzinski M, Zettler CG. The effect of neoadjuvant chemotherapy on hormone receptor status, HER2/neu and prolactin in breast cancer. Tumouri. 2011; 97 (6):704-10.

[33] Hawkins RA, Tesdale AL, Anderson ED, Levack PA, Chetty U, Forrest AP. Does the oestrogen receptor concentration of a breast cancer change during systemic therapy? $\mathrm{Br} \mathrm{J}$ Cancer 1990; 61(6):877e80.

[34] Yang YF, Liao YY, Li LQ, Xie SR, Xie YF, Peng NF. Changes in ER, PR and HER2 receptors status after neoadjuvant chemotherapy in breast cancer. Pathol Res Pract 2013; 209(12):797e802.

[35] Cockburn A, Yan J, Rahardja D, Euhus D, Peng Y, Fang Y, et al. Modulatory effect of neoadjuvant chemotherapy on biomarkers expression; assessment by digital image analysis and relationship to residual cancer burden in patients with invasive breast cancer. Hum Pathol 2014; 45(2):249e58.

[36] Adams AL, Eltoum I, Krontiras H, Wang W, Chhieng DC. The effect of neoadjuvant chemotherapy on histologic grade, hormone receptor status, and HER2/neu status in breast carcinoma. Breast J 2008; 14 (2):141e6.

[37] Hirata T, Shimizu C, Yonemori K, Hirakawa A, Kouno T, Tamura $\mathrm{K}$, et al. Change in the hormone receptor status following administration of neoadjuvant chemotherapy and its impact on the long-term outcome in patients with primary breast cancer. Br J Cancer 2009; 101(9):1529e36.

[38] Vincent-Salomon A, Jouve M, Genin P, Freneaux P, SigalZafrani B, Caly M, et al. HER2 status in patients with breast carcinoma is not modified selectively by preoperative chemotherapy and is stable during the metastatic process. Cancer 2002; 94(8):2169e73.

[39] Mittendorf EA, Wu Y, Scaltriti M, Meric-Bernstam F, Hunt KK, Dawood S, et al. Loss of HER2 amplification following trastuzumab-based neoadjuvant systemic therapy and survival outcomes. Clin Cancer Res 2009; 15 (23):7381e8.

[40] Bines J, Oleske DM, Cobleigh MA. Ovarian function in premenopausal Women treated with adjuvant chemotherapy for breast cancer. J Clin Oncol 1996; 14 (5):1718e29. 
[41] Dati C, Antoniotti S, Taverna D, Perroteau I, De Bortoli M. Inhibition of c-erbB-2 oncogene expression by estrogens in human breast cancer cells. Oncogene 1990; 5(7):1001e6.

[42] Van Poznak C, Somerfield MR, Bast RC, Cristofanilli M,
Goetz MP, Gonzalez-Angulo AM, et al. Use of Biomarkers to Guide Decisions on Systemic Therapy for Women With Metastatic Breast Cancer: American Society of Clinical Oncology Clinical Practice Guideline. J Clin Oncol. 2015; 33:2695-704. 